\title{
Are Tattoos an Indicator of Severity of Non-Suicidal Self-Injury Behavior in Adolescents?
}

\author{
Marco Antonio Solís-Bravo ${ }^{1,2}$, Yassel Flores-Rodríguez ${ }^{1,3}$, Liliana Guadalupe Tapia-Guillen ${ }^{1,2}$, \\ Aymara Gatica-Hernández ${ }^{1,4}$, Miriam Guzmán-Reséndiz ${ }^{1,5}$, Luis Alberto Salinas-Torres ${ }^{1,6}$, \\ Tania Lucila Vargas-Rizo', and Lilia Albores-Gallo, ${ }^{1,7} \bowtie$ \\ ${ }^{1}$ Hospital Psiquiátrico Infantil "Dr. Juan N. Navarro", Mexico City, Mexico \\ ${ }^{2}$ Clinical and Community Epidemiology in Child and Adolescent Psychiatry, Universidad Nacional Autónoma de Mexico, Mexico City, Mexico \\ ${ }^{3}$ Hospital Psiquiátrico "Dr. Samuel Ramírez Moreno", Mexico State, Mexico \\ ${ }^{4}$ Instituto Nacional de Psiquiatría "Dr. Ramón de la Fuente Muñiz", Mexico City, Mexico \\ ${ }^{5}$ Hospital General "Dr. Ruben Leñero", Mexico City, Mexico \\ ${ }^{6}$ CECOSAM Cuauhtémoc, Mexico City, Mexico \\ ${ }^{7}$ Clinical and Community Epidemiology in Child and Adolescent Psychiatry, Universidad Nacional Autónoma de Mexico, Mexico City, Mexico
}

Objective To compare adolescents with non-suicidal self-injury behavior and tattoos [NSSI $(\mathrm{T}+)$ ] with another group with non-suicidal self-injury behavior without tattoos [NSSI (T-)].

Methods Adolescents $(n=438) 42.6 \%$ males from the community (M=12.3, SD=1.3), completed the Self-Injury Schedule.

Results The lifetime prevalence of tattoos performed with the purpose to feel pain was $1.8 \%$. Compared to the NSSI (T-) group, the NSSI $(\mathrm{T}+)$ group was significantly more likely to meet the DSM- 5 frequency criteria of 5 self-injury events in 1 year, practice more than one method of self-injury, and topography, more suicidal intentionality, more negative thoughts and affective emotions before, during, and after self-injury and more academic and social dysfunction.

Conclusion Adolescents from the community who practice tattooing to feel pain, show a distinct phenotype of NSSI. Health professionals and pediatricians should assess tattooing characteristics such as intention (to feel pain), frequency, and presence of non-suicidal self-injury behavior and suicide intentionality.

Psychiatry Investig 2019;16(7):504-512

Key Words Tattoo, Self-injury, Suicide, Child and adolescence psychiatry, Prevalence.

\section{INTRODUCTION}

Prevalence of tattooing in the general population it is between $6 \%$ to $24 \%$, ${ }^{1}$ in clinical samples of adolescents it is between $4.5 \%$ and $13.2 \%,{ }^{2-5}$ the highest figures are reported in young adults, and militia-related individuals. ${ }^{5,6}$

Recent studies show an association between tattooing and psychiatric disorders, such as depression ${ }^{7}$ anxiety, eating disorders $^{5}$ and risky behaviors like substance use, ${ }^{5,8-12}$ promiscuity, ${ }^{11,13}$ suicidal thinking and attempted suicide. ${ }^{5,7,9,14,15}$

\footnotetext{
Received: October 24, 2018 Revised: December 17, 2018 Accepted: March 6, 2019

$\square$ Correspondence: Lilia Albores-Gallo, MD, $\mathrm{PhD}$

Departamento de Epidemiología Genética, Clínica y Comunitaria; Hospital Psiquiátrico Infantil "Dr. Juan N. Navarro" San Buenaventura 86, Belisario Domínguez, Tlalpan 14080, Ciudad de México, México

Tel: +525523162517, Fax: +5255739161, E-mail: lilialbores@gmail.com

(c) This is an Open Access article distributed under the terms of the Creative Commons Attribution Non-Commercial License (https://creativecommons.org/licenses/bync/4.0) which permits unrestricted non-commercial use, distribution, and reproduction in any medium, provided the original work is properly cited.
}

Adult tattoo users report self-injury behavior more frequently, ${ }^{16,17}$ sharing psychological precipitants such as negative thoughts of anxiety, tension, anger, distress or depression and interpersonal difficulties before the act. ${ }^{16,18}$ These association has been poorly studied in adolescents, although, research suggests those who acquire permanent tattoos during adolescence, specially at earlier ages (11-16 years), have more risk factors for psychopathology and other negative outcomes and engage more frequently in risky behaviors. ${ }^{4,5,9,19,20}$

Tattoos and piercings have been considered as methods of self-harm, but, they may have social acceptance in some cultures; ${ }^{21,22}$ this explains why under the Diagnostic and Statistical Manual of Mental Disorders 5th Edition (DSM-5), ${ }^{23}$ tattoos were excluded from the non-suicidal self-injury (NSSI) condition, specifically mentioned in criterion D: "Behavior (self-injury) is not socially accepted (as an example, piercings, tattoos, part of a religious or cultural ritual...)."

The aim of this study was to compare the characteristics of 
NSSI behavior with and without tattoos performed with the intention to feel pain in a sample of Mexican adolescents.

The Research and Ethics Committee of the participating institutions approved the study (II1/01/1013).

\section{Hypothesis}

If the presence of tattoos is associated with risky behaviors in adolescents, then, adolescents who tattoo themselves with the intention to feel pain and practice NSSI will injure more often, in more anatomical sites, experience more negative feelings and cognitive states and greater dysfunction.

\section{METHODS}

A survey with a cross-sectional and comparative design was conducted involving adolescents $(n=438)$ between 11 and 17 years of age, with a mean age of 12.3 years (SD 1.3), $57.2 \%$ were female $(n=251)$.

\section{Instruments}

\section{The Non-Suicide Self-Injury Schedule (NSSI-S) ${ }^{24}$}

The instrument is based on the DSM-5 criteria for NSSI, it contains 31 dichotomous items with a yes/no response format to explore the DSM-5 dimensions of self-injuring: B1: Psychological precipitants, B2: Concerns, B3: Urgencies, B4: Contingent responses, C1: Interpersonal difficulties, C2: Preoccupation with the behavior, C3: Frequent thoughts about self-injuring, E: Impairment and some explanatory variables. The frequency of self-injuring according to DSM-5 Criteria; the methods and topography; the emotions present before, during and after self-injuring; the associated addictive component; the triggering and mitigating factors for self-injuring; the suicidal intentionality and the age of onset of the behavior.

Cases were assigned to two groups if they gave a positive answer to item 1: "Do you hurt yourself without the intention to die?" and answered yes/no to item 31: "Did you ever get a tattoo to feel pain?" Group 1) students with non-suicidal self-injury and tattoos with the intention to feel pain [NSSI $(\mathrm{T}+)$ ] and group 2) students with non-suicidal self-injury without tattoos [NSSI (T-)].

\section{Procedure}

After obtaining approval from administrators of two public high schools and parents, those who agreed to participate signed an informed consent. Students gave their assent and completed the instrument in their classrooms. All participants received information on how to seek attention in our institution.

\section{Statistical analysis}

Categorical demographic variables were analyzed using frequencies and percentages, and continuous variables were analyzed using the Student t-test. The chi-square or Fisher test was used for categorical variables and unadjusted odds ratios were calculated to measure the effect size of the association between practicing non-suicidal self-injury behavior and tattoos to feel pain (yes/no) and the rest of the variables of the NSSI-S. A statistical significance level of $\mathrm{p}=0.05$ was established.

An algorithm was used to perform the statistical analysis used in this study as follows: Dimension A explores the methods used for self-injury through items 5-16. The higher the score, the more serious the self-harmful behavior. The 12 items were added, and a new binary variable was created recoding to $0=$ those who do not injure themselves and $1=$ those who injured themselves with one or more methods. Items 2-4 inquire about frequency according to DSM-5 criteria.

Dimension B evaluates the contingent response through items 17-22, which were added, and a new binary variable was recoded assigning to 0 those with no feelings or cognitive states and 1 to those presenting one or more negative feeling or cognition.

Dimension C explores if the behavior is associated with at least one of the following: interpersonal difficulties or negative feelings or thoughts.

Criterion D was excluded for the purpose of this research.

Dimension E assesses social, school and daily living impairment in the school area, other activities of daily living (resting, sleeping) and in the social environment, through items 23-25; the items were added, and a new binary variable was recoded assigning a 0 to those who had no social, school and daily living dysfunction and 1 to those who had more than one.

\section{RESULTS}

The prevalence of NSSI was $11.5 \%(n=50)$, while $1.8 \%(n=8)$ reported having a tattoo performed with the intention to feel pain. The frequency of tattooing was larger in males compared to females $(2.2 \%$ vs. $1.6 \%)$, but this difference did not reach statistical significance.

The presence of NSSI behavior was larger in students with tattoos $(62.5 \%)$ than in adolescents without them $(10.6 \%)$ (OR:14; 95\% CI: 3.2-60.5; p=0.001), Figure 1 shows a comparison of the number of self-injuring events per month, 6 months and 12 months for each group.

The DSM-5 frequency criterion (5 events per year) was higher in the NSSI $(\mathrm{T}+)$ group compared to the NSSI (T-), 75\% vs. $7.7 \%$ respectively (OR: 35.7 ; 95\% CI: 6.9-184); in the last month, $62.5 \%$ vs. $6.1 \%$ (OR: 25.5 ; 95\% CI: $5.7-112.9$ ) and in 
the previous 6 months, 50\% vs 9.4\% (OR: 9.6; 95\% CI: $2.3-$ 40) (Figure 1).

Table 1 shows the results of comparing the NSSI (T-) and NSSI $(\mathrm{T}+)$ groups according to the method and topography of self-injury.

\section{Method of self-injury}

The NSSI $(\mathrm{T}+)$ group was significantly more likely to practice all methods of self-injury, with the top three including

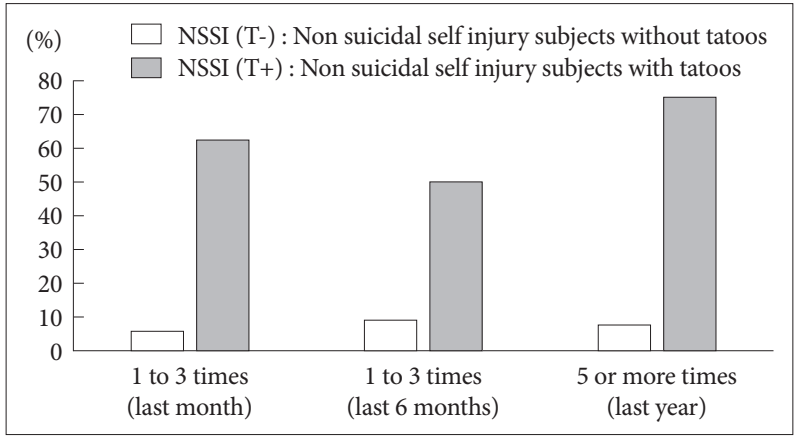

Figure 1. Frequency of events by group. sticking objects under the skin (OR: 29; 95\% CI: 6.5-129.1), using objects to mark the skin or nails (OR: 17; 95\% CI: 3.973.9) and rubbing the skin (OR: 13.4; 95\% CI: 3.1-58\%).

\section{Topography}

The NSSI $(\mathrm{T}+)$ group was significantly more likely to selfinjure in buttocks and/or genitals (OR: 252.6; 95\% CI: 40.61570.1), face (OR: 87.8; 95\% CI: 16.2-474.5), head (OR: 29.4; 95\%CI: 6.6-129.8) and arms and elbows (OR: 26.9; 95\% CI: 6.1-118.1).

\section{DSM-5 criteria}

\section{Psychological precipitants}

The results of the comparison between the NSSI (T-) and NSSI $(\mathrm{T}+)$ groups on psychological precipitants are reported in Table 2. Compared to the NSSI (T-) group, the NSSI ( $\mathrm{T}+$ ) group was significantly more likely to have negative emotional and cognitive states before, during, and after the selfinjury. The effect size was higher for feelings of anxiety (OR: 40.1; 95\% CI: 7.4-217.0), self-criticism (OR: 38.2; 95\% CI:

Table 1. Characteristics of NSSI

\begin{tabular}{|c|c|c|c|c|c|}
\hline \multirow{2}{*}{ Variables } & \multicolumn{2}{|c|}{ Tattoos to feel pain } & \multirow{2}{*}{ OR $(95 \% \mathrm{CI})$} & \multirow{2}{*}{$\chi^{2}$} & \multirow{2}{*}{$\mathrm{p}$} \\
\hline & No $(\%)$ & Yes $(\%)$ & & & \\
\hline \multicolumn{6}{|l|}{ Method } \\
\hline Cutting & 9.9 & 50.0 & $9.1(2.2-37.8)$ & 13.31 & 0.006 \\
\hline Rubbing & 11.0 & 62.5 & $13.4(3.1-58.0)$ & 19.72 & 0.001 \\
\hline Inserting objects under the skin and nails & 5.4 & 62.5 & $29(6.5-129.1)$ & 42.19 & 0.0001 \\
\hline Picking & 16.0 & 50.0 & $5.2(1.2-21.4)$ & 6.52 & 0.029 \\
\hline Using objects to mark the skin & 8.9 & 62.5 & $17(3.9-73.9)$ & 25.25 & 0.0001 \\
\hline Scratching & 26.7 & 37.5 & $1.6(0.38-6.9)$ & 0.46 & 0.369 \\
\hline Pulling the skin that peels after sunburn & 19.1 & 37.5 & $2.5(0.59-10.8)$ & 1.70 & 0.188 \\
\hline Burning the skin with cigarettes or corrosive substances & 3.5 & 28.6 & $10.9(1.9-60.8)$ & 11.39 & 0.027 \\
\hline $\begin{array}{l}\text { Plucking hair, eyelashes or eyebrows? } \\
\text { (excluding cosmetic reasons) }\end{array}$ & 4.7 & 25.0 & $6.7(1.2-35.4)$ & 6.68 & 0.058 \\
\hline Ripping off nails & 6.8 & 25.0 & $4.5(0.87-23.5)$ & 3.88 & 0.106 \\
\hline Biting & 16.7 & 37.5 & $2.9(0.69-12.7)$ & 2.38 & 0.142 \\
\hline Hitting body or head or slapping & 11.1 & 50.0 & $8.0(1.9-33.2)$ & 11.45 & 0.008 \\
\hline \multicolumn{6}{|l|}{ Topography } \\
\hline Forearms and wrists & 7.5 & 42.9 & $9.1(1.9-42.8)$ & 11.50 & 0.001 \\
\hline Arms and elbows & 3.6 & 50.0 & $26.9(6.1-118.1)$ & 39.78 & 0.0001 \\
\hline Thighs and knees & 4.2 & 42.9 & $17.0(3.5-81.6)$ & 22.27 & 0.003 \\
\hline Abdomen and thorax (chest or back) & 2.8 & 42.9 & $25.8(5.2-128.5)$ & 33.01 & 0.001 \\
\hline Face & 3.3 & 75.0 & $87.8(16.2-474.5)$ & 91.41 & 0.0001 \\
\hline Head & 3.3 & 50.0 & $29.4(6.6-129.8)$ & 43.10 & 0.0001 \\
\hline Buttocks or genitals & 1.2 & 75.0 & $252.6(40.6-1570)$ & 173.25 & 0.0001 \\
\hline
\end{tabular}

NSSI: non suicidal self injury, OR: odds ratio, CI: confidence interval 
7.4-197.3) and tension (OR: 29.2; 95\% CI: 6.5-129.8) before the behavior.

\section{Addictive component}

The NSSI $(\mathrm{T}+)$ group reported more addictive features, like feelings of addiction to self-injurious behavior (OR: 55.1; 95\% CI: 10.0-303.7), being unable to stop doing the self-injurious act (OR: 8.7; 95\% CI: 2.1-36.3) and desire to stop doing the self-injurious act (OR: 7.2; 95\% CI: 1.5-33.1) (Table 3).

Table 4 shows the groups comparison between DSM- 5 criteria for Dimension A, Dimension B (B1, B2 y B3), Dimension $\mathrm{C}(\mathrm{C} 1, \mathrm{C} 2, \mathrm{C} 3)$ and Dimension $\mathrm{E}$.

\section{Dimension A}

Compared to the NSSI (T-) group, the NSSI (T+) self-injured more frequently (Dimension A) (OR: 7.9; 95\% CI: 1.0-64.8).

\section{Dimension B}

The NSSI $(\mathrm{T}+)$ reported a larger percentage of contingent responses to self-jury (Dimension B), such as: Releasing negative feelings (B1) (OR: 15.2; 95\% CI: 3.5-66), Resolving interpersonal difficulties (B2) (OR: 14.1; 95\% CI: 3.3-59.5) and Induction of positive feelings (B3) (OR: 19; 95\% CI: 4.1-88.1).

\section{Dimension C}

The NSSI $(\mathrm{T}+)$, had a larger percentage of negative emo-

Table 2. Psychological precipitants of NSSI

\begin{tabular}{|c|c|c|c|c|c|}
\hline \multirow{2}{*}{ Variables } & \multicolumn{2}{|c|}{ Tattoos to feel pain } & \multirow{2}{*}{ OR $(95 \% \mathrm{CI})$} & \multirow{2}{*}{$\chi^{2}$} & \multirow{2}{*}{$\mathrm{p}$} \\
\hline & No (\%) & Yes $(\%)$ & & & \\
\hline \multicolumn{6}{|l|}{ Feelings and cognitive states before NSSI } \\
\hline Negative feelings or thoughts & 12.7 & 62.5 & $11.4(2.6-49.2)$ & 16.54 & 0.002 \\
\hline Depression & 9.9 & 62.5 & $15.1(3.5-65.8)$ & 22.46 & 0.001 \\
\hline Anxiety & 5.9 & 71.4 & $40.1(7.4-217.0)$ & 45.90 & 0.0001 \\
\hline Tension & 5.4 & 62.5 & $29.2(6.5-129.8)$ & 42.42 & 0.0001 \\
\hline Anger & 10.3 & 62.5 & $14.4(3.3-62.6)$ & 21.34 & 0.001 \\
\hline Stress & 6.6 & 62.5 & $23.6(5.3-104.2)$ & 34.96 & 0.0001 \\
\hline Self-criticism & 7.3 & 75.0 & $38.2(7.4-197.3)$ & 46.18 & 0.0001 \\
\hline Resistance to perform this behavior & 8.3 & 50.0 & $11.1(2.6-46.3)$ & 16.66 & 0.003 \\
\hline \multicolumn{6}{|l|}{ Feelings and cognitive states during NSSI } \\
\hline Preoccupation about the behavior & 12.3 & 37.5 & $4.2(0.99-18.4)$ & 4.50 & 0.069 \\
\hline Relief of tension & 5.4 & 25.0 & $5.8(1.1-30.5)$ & 5.55 & 0.072 \\
\hline \multicolumn{6}{|l|}{ Feelings and cognitive states after NSSI } \\
\hline Preoccupation about the behavior & 14.4 & 50.0 & $5.9(1.4-24.3)$ & 7.76 & 0.021 \\
\hline Relief of tension immediately after & 6.6 & 37.5 & $8(1.9-37.2)$ & 11.21 & 0.015 \\
\hline \multicolumn{6}{|l|}{ Motivations for NSSI } \\
\hline Relief from negative feelings & 8.5 & 50.0 & $10.7(2.5-44.9)$ & 16.10 & 0.003 \\
\hline Relief from negative thoughts & 7.3 & 37.5 & $7.6(1.7-33.4)$ & 9.90 & 0.019 \\
\hline Relief from personal difficulties & 6.6 & 50.0 & $14.1(3.3-59.5)$ & 21.55 & 0.001 \\
\hline Induce positive feelings & 3.1 & 37.5 & $19.0(4.1-88.1)$ & 26.17 & 0.002 \\
\hline $\begin{array}{l}\text { Need to perform the act frequently } \\
\text { (even if not always executed) }\end{array}$ & 7.1 & 25.0 & $4.3(0.84-22.6)$ & 3.69 & 0.112 \\
\hline
\end{tabular}

NSSI: non suicidal self injury, OR: odds ratio, CI: confidence interval

Table 3. Addictive component of NSSI

\begin{tabular}{|c|c|c|c|c|c|}
\hline \multirow{2}{*}{ Variables } & \multicolumn{2}{|c|}{ Tattoos to feel pain } & \multirow{2}{*}{ OR $(95 \% \mathrm{CI})$} & \multirow{2}{*}{$\chi^{2}$} & \multirow{2}{*}{$\mathrm{p}$} \\
\hline & No $(\%)$ & Yes $(\%)$ & & & \\
\hline Feeling they can't stop self-injuring & 10.2 & 50.0 & $8.7(2.1-36.3)$ & 12.66 & 0.006 \\
\hline Feelings of addiction to self-injuring & 4.3 & 71.4 & $55.1(10.0-303.7)$ & 60.13 & 0.0001 \\
\hline Desire to stop self-injuring & 15.5 & 57.1 & $7.2(1.5-33.1)$ & 8.76 & 0.015 \\
\hline
\end{tabular}

NSSI: non suicidal self injury, OR: odds ratio, CI: confidence interval 
tions and cognitive states associated with NSSI, including interpersonal difficulties, negatives feelings or thoughts (OR: 33.8; 95\% CI: 4.1-279.3), and preoccupation with the intended behavior that is difficult to control (OR:11.1, 95\% CI: 2.6-46.3) (Tables 2 and 4).

\section{Dimension E}

The NSSI $(\mathrm{T}+)$, had more impairment (Dimension E) on Academic activities (OR: 95.3, 95\% CI: 17.5-517.9), Interpersonal relationships (OR: 22.3; 95\% CI: 4.7-105.4), and Rest and sleep (OR: 29.2; 95\% CI: 6.6-128.9).

\section{Suicidal intention}

The NSSI $(\mathrm{T}+)$ group was more likely to self-injure without suicidal intent, $62.5 \%$ compared to $10.6 \%$ of the NSSI (T-) but also reported more suicidal thoughts during the self-injurious behavior, $50 \%$ vs $4.9 \%$ (OR: 19.2; 95\% CI: 4.4-82.3). The majority of the NSSI $(\mathrm{T}+$ ) had more suicidal intent $(87.5 \%)$ when self-injuring compared to only $2.1 \%$ of the NSSI (T-) (OR: 323.5; 95\% CI: 35.9-2911.0) (Table 5).

\section{DISCUSSION}

This study demonstrated differences in the characteristics of self-injury behavior in two groups of adolescents who practice self-harm with and without tattoos: NSSI (T+) and NSSI (T-). The lack of similar studies makes it hard to compare our results.

In our study, the frequency of tattoos with the intention to feel pain in the total sample was $1.8 \%$ which is similar to adolescents of the community from Chile (1.7\%) and Taiwan (1\%). ${ }^{25,26}$ Turkey and Canada reported a higher prevalence $(4.8 \%$ and $7.9 \%),{ }^{4,10}$ but these studies assessed how frequently the participants got tattoos but not the motivating factors for getting tattooed.

In our study, the prevalence of tattoos performed to feel pain in adolescents with NSSI in the community was higher (10\%); this figure approximates the prevalence in clinical samples, however, most of the studies included adults. ${ }^{2,3,27}$

In our study, the frequency of tattoos by sex (male $2.2 \%$ vs. girls $1.6 \%$ ) showed no significant differences, this result is consistent with other studies in the community and in clinical samples. ${ }^{4,10,17,20}$ In contrast, other research shows increased frequency in females. $9,11,28-32$

Table 4. NSSI dimensions

\begin{tabular}{|c|c|c|c|c|c|}
\hline \multirow{2}{*}{ Dimension } & \multicolumn{2}{|c|}{ Tattoos to feel pain } & \multirow{2}{*}{$\mathrm{OR}(95 \% \mathrm{CI})$} & \multirow{2}{*}{$\chi^{2}$} & \multirow{2}{*}{$\mathrm{p}$} \\
\hline & No (\%) & Yes (\%) & & & \\
\hline A Frequency of self-injury & 46.9 & 87.5 & $7.9(1-64.8)$ & 5.17 & 0.030 \\
\hline \multicolumn{6}{|l|}{ B Contingent response to self-injury } \\
\hline B1 Relief from negative feelings (-) & 9.9 & 62.5 & $15.2(3.5-66.0)$ & 22.53 & 0.001 \\
\hline B2 Resolution Interpersonal Difficulties & 6.6 & 50.9 & $14.1(3.3-59.5)$ & 21.55 & 0.001 \\
\hline B3 Induction of Positive Feelings & 3.1 & 37.5 & $19.0(4.1-88.1)$ & 26.1 & 0.002 \\
\hline \multicolumn{6}{|l|}{ C Affects and Cognitions Associated to NSSI } \\
\hline C1 Interpersonal difficulties or negative feelings or thoughts & 17.1 & 87.5 & $33.8(4.1-279.3)$ & 25.85 & 0.0001 \\
\hline C2 Period of preoccupation & 8.3 & 50.0 & $11.1(2.6-46.3)$ & 16.6 & 0.003 \\
\hline C3 NSSI Rumination & 7.1 & 25.0 & $4.3(0.849-22.6)$ & 3.69 & 0.112 \\
\hline \multicolumn{6}{|l|}{ E Impairment } \\
\hline E1 Interpersonal & 5.6 & 57.1 & $22.3(4.7-105.4)$ & 30.2 & 0.0001 \\
\hline E2 Academic & 3.1 & 75 & $95.3(17.5-517.9)$ & $\mathrm{F}$ & 0.0001 \\
\hline E3 Other areas & 3.3 & 50 & $29.2(6.6-128.9)$ & $\mathrm{F}$ & 0.0001 \\
\hline
\end{tabular}

NSSI: non suicidal self injury, OR: odds ratio, CI: confidence interval

Table 5. Suicidal Intent

\begin{tabular}{|c|c|c|c|c|c|}
\hline \multirow{2}{*}{ Variables } & \multicolumn{2}{|c|}{ Tattoos to feel pain } & \multirow{2}{*}{ OR $(95 \% \mathrm{CI})$} & \multirow{2}{*}{$\chi^{2}$} & \multirow{2}{*}{$\mathrm{p}$} \\
\hline & No $(\%)$ & Yes $(\%)$ & & & \\
\hline Self-injuries with the intention to die & 2.1 & 87.5 & $323.5(35.9-2911.0)$ & 160.8 & 0.0001 \\
\hline Self-injuries without the intention to die & 10.6 & 62.5 & $14(3.2-60.5)$ & 20.5 & 0.001 \\
\hline Suicidal thoughts when self-injuring without the intention to die & 4.9 & 50.0 & $19.2(4.4-82.3)$ & 29.3 & 0.0001 \\
\hline
\end{tabular}

OR: odds ratio, CI: confidence interval 


\section{DSM-5 criteria}

\section{Dimension A}

The NSSI $(\mathrm{T}+)$ group met the DSM- 5 frequency criteria of 5 events per year proposed by Shaffer ${ }^{33,34}$ which seems to identify individuals with more severe self-injury phenotypes. For example Dulit et al., ${ }^{35}$ studied a large group of patients with borderline personality disorder and those who reported 5 self-injury events in one year were more likely to have another psychiatric disorder, these findings have been confirmed in later studies, ${ }^{36,37}$ but opposing results have also been reported by Muehlenkamp et al..$^{38}$ who, in a clinical study of adolescents, proposed raising the frequency threshold of the
DSM- 5 criteria arguing that 5 events per year over-pathologize the behavior, an opinion shared by other researchers. ${ }^{39,40}$ Further research comparing clinical and community samples is necessary.

We also found that adolescents who performed tattoos to feel pain chose different methods of self-injury (inserting objects under the skin and nails, using objects to mark the skin, burning) compared to adolescents without tattoos who selfinjure (scratching, cutting, rubbing and picking the skin) reported by other researchers. ${ }^{41-44}$ Similar results were reported by Iannaccone et al., ${ }^{45}$ who found a high correlation between burns and tattoos in women with eating behavior disorder.

Table 6. Non-suicide self-injury schedule

\begin{tabular}{|c|c|}
\hline Item & Question \\
\hline 1 & Do you hurt yourself without the intention to die? \\
\hline 2 & In the last month, have you hurt yourself one to three times? \\
\hline 3 & In the last 6 months, have you hurt yourself one to three times? \\
\hline 4 & In the last year, have you hurt yourself five or more times? \\
\hline 5 & Have you cut your skin? \\
\hline 6 & Have you rubbed your skin with an object? \\
\hline 7 & Have you inserted any object under your skin or nails? \\
\hline 8 & Have you picked your skin? \\
\hline 9 & Have you ever used any object (pencil, compass, needle, cutter, others...) to mark your skin? \\
\hline 10 & Have you scratched scars? \\
\hline 11 & Have you pulled the skin that peels after sunburn? \\
\hline 12 & Have burned your skin with cigarettes or corrosive substances? \\
\hline 13 & Have you plucked your hair, eyebrows or eyelashes (excluding cosmetic reasons)? \\
\hline 14 & Have you ripped off your nails? \\
\hline 15 & Have you bitten yourself? \\
\hline 16 & Have you hit your body or head or slapped yourself? \\
\hline 17 & Do you perform these acts to hurt yourself because they release you from negative feelings? \\
\hline 18 & Do you perform these acts to hurt yourself because they release you from negative thoughts? \\
\hline 19 & Do you perform these acts to hurt yourself because they release you from personal difficulties? \\
\hline 20 & Do you perform these acts to hurt yourself because they induce positive feelings? \\
\hline 21 & Do you feel a relief of tension during the act of harming yourself? \\
\hline 22 & Do you feel a relief of tension immediately after the act of harming yourself? \\
\hline 23 & Does the act of self-injuring interfere with your academic duties? \\
\hline 24 & Does the act of self-injuring interfere with your rest or sleep? \\
\hline 25 & Does the act of self-injuring interfere with your interpersonal relationships? \\
\hline 26 & Do you feel you can’t stop self-injuring? \\
\hline 27 & Do you feel you're addicted to self-injuring? \\
\hline 28 & Do you want to stop self-injuring? \\
\hline 29 & Do you hurt yourself with the intention to die? \\
\hline 30 & When you hurt yourself without the intention to die, do you have suicidal thoughts? \\
\hline 31 & Did you ever get a tattoo to feel pain? \\
\hline
\end{tabular}




\section{Topography}

The NSSI $(\mathrm{T}+)$ group was more likely to self-injure in all parts of the body involving buttocks/genitals, face, and head. Contrasting with the NSSI(T-) group in which forearms and wrists were preferred body locations, which is consistent with other research. ${ }^{41,43,46,47}$

Although research is lacking, clinical experience suggests that self-injuring in face, breasts, eyes, and genitals is of special concern because it implies a higher level of psychological distress. $^{48}$

\section{Dimensions B and C}

In comparison to the NSSI (T-) adolescents in the NSSI $(\mathrm{T}+)$ group met the majority of DSM-5 criteria included in dimension B. B1: Release of negative feelings or cognitions; B2: Resolution of interpersonal difficulties; B3: Induction of positive feelings. Likewise, concerning Dimension C, the NSSI $(\mathrm{T}+)$ group reported higher frequencies of negative thoughts and feelings; which is similar to the findings reported by Aizenman and Jensen, ${ }^{16}$ who found tattooed college students who also self-injure had higher depression, lower self-esteem and mastery/control scores.

\section{Addictive component (Table 3)}

Compared to the NSSI (T-) group, the NSSI $(\mathrm{T}+)$ showed a higher frequency of addictive component (10.2\% vs. $50 \%$ respectively) which was investigated through items 26-28 (Table 6). This is congruent with previous clinical research where addictive features are present in 10-97\% of adolescents who practice NSSI; ${ }^{49,50}$ and also with a review by Bunderla and Gregorič ${ }^{51}$ who reported 5 studies showing higher pain threshold and longer pain tolerance in NSSI subjects. These results are consistent with a study of young college students, where $48.5 \%$ reported addictive features to tattooing behavior. ${ }^{11}$

\section{Dimension E social dysfunction}

It is difficult to contrast our results with the few studies that have investigated the DSM-5 criteria in adolescents with NSSI. Increased absenteeism and dropout rates among tattooed adolescents are common. ${ }^{2,3,9,15,51}$ These findings support school dysfunction, however, in a Mexican with young adults, Benjet et al. ${ }^{52}$ suggested that individuals may not perceive this behavior as dysfunctional because it is used as an effective strategy to deal with unpleasant feelings, cognitions and interpersonal or family difficulties. In our sample, impairment was less frequent among those who self-injure without tattoos $(18.3 \%$ compared to 39.9 of the Mexican sample of young adults). ${ }^{52}$ These differences could suggest adolescents have less awareness or normalize the behavior due to peer pressure or a desire for group integration. As Benjet et al. ${ }^{52}$ points out, low perception of impairment is an obstacle for seeking treatment.

\section{Severity indicators}

Compared to the NSSI (T-) group, the NSSI ( $\mathrm{T}+$ ) group presented other indicators of self- injury severity, such as using more than one method, more anatomical sites, more frequent events and a greater propensity to suicide intent (87.5\%); this is consistent with other studies that show teens and young adults with tattoos are at increased risk of suicide attempts and unhealthy practices. ${ }^{5,7,918,26,32,53,54}$ However, the evidence is conflicting because other authors do not report this association. ${ }^{11,55}$ Some researchers show tattoos could be a protective or mitigating factor for suicidal ideation and attempts. ${ }^{27}$ Moreover, there is evidence of a decline and extinction of self-injurious behavior after tattooing ${ }^{18}$ and most tattooed teens do not harm themselves, only $33 \%$ show selfinjury practices. ${ }^{8}$ More research is needed to better characterize which individuals are more prone to engaging in suicidal behavior and other risk factors.

We also found that a high percentage of tattooed adolescents with NSSI have more suicide intent suggesting that suicide intent and NSSI are overlapping and therefore extremely difficult to differentiate due to its alternating nature, this explains why studies show that adolescents with NSSI are at higher risk of suicide. ${ }^{56}$

The significance of our results is that health personnel and adults involved with the care of children and adolescents with tattoos should intentionally inquire about self-injurious behavior, and if present, investigate about risk behavior such as low academic achievement, unprotected sex, substance abuse, promiscuity, eating disorders, accidents and suicidal intent. $^{4,5,9,15,18,45,54}$

\section{Limitations}

The presence of tattoos was investigated through self- report and no visual confirmation was performed as some studies have done in clinical samples where the context is adequate for a physical examination.

We did not ask if the teenagers had requested permission from their parents prior to the tattooing process. There is evidence that around $83 \%$ of adolescents do not have permission from their parents to obtain a tattoo. ${ }^{57}$

In Mexico, the practice of tattooing is prohibited in minors under 18 years of age, unless they are accompanied by their parents or guardians; after signing an informed consent letter, and a prior sanitary questionnaire and letter of authorization are completed. ${ }^{38}$ Some studies show that more than $60 \%$ of adolescents do not ask their parents for permission to get a tattoo,,$^{27,57,58}$ although others report opposite findings ${ }^{2,51}$ this 
is important because adolescents who do not ask for permission could also engage in more risky behavior than their peers who do not get tattoos or do so with proper authorization. Also, our small sample size precludes us from analyzing adolescents who tattoo themselves without the intention to feel pain and who engage in NSSI.

\section{Conclusions}

Our results support the idea that tattoos performed for feeling pain are a correlate of non-suicidal self-injury behavior, since they share DSM-5 characteristics, as frequency, and greater severity in most of variables. Hence the importance of asking the purpose behind getting a tattoo, whether they practice self-harm and assessing suicidal intentionality. Our findings also suggest that a group of individuals could engage in tattooing as a form of NSSI and further research could warrant adding a specifier in Diagnostic Criteria.

\section{Acknowledgments}

We the authors are grateful to all the families who participated in this study.

\section{Conflicts of Interest}

The authors have no potential conflicts of interest to disclose.

\section{Author Contributions}

Conceptualization: Lilia Albores-Gallo. Data curation, Formal analysis, Investigation, Methodology: Marco Antonio Solís-Bravo, Yassel FloresRodríguez, Liliana Guadalupe Tapia-Guillen, Aymara Gatica-Hernández, Miriam Guzmán-Reséndiz, Lilia Albores-Gallo. Project administration: Lilia Albores-Gallo. Writing_original draft: Marco Antonio Solís-Bravo, Yassel Flores-Rodríguez, Liliana Guadalupe Tapia-Guillen. Writing-review \& editing: Aymara Gatica-Hernández, Miriam Guzmán-Reséndiz, Luis Alberto Salinas-Torres, Tania Lucila Vargas-Rizo.

\section{ORCID iDs}

Lilia Albores-Gallo https://orcid.org/0000-0001-5862-4404

Marco Antonio Solís-Bravo https://orcid.org/0000-0002-2692-1452

\section{REFERENCES}

1. Serup J, Kluger N, Baumler W. Current Problems in Dermatology. 1st Edition. Epidemiology of Tattoos in Industrialized Countries. In: Kluger N, Editor. Tattooed Skin and Health. Basel: Karger Publishers, 2015, p. 6-20.

2. Busaniche JN, Eymann AM, Mulli V, Paz MC, Catsicaris C. Asociación entre adolescentes tatuados y conductas de riesgo. Arch Argent Pediatr 2006;104:309-315.

3. Farrow JA. Tattooing behavior in adolescence: a comparison study. Am J Dis Child 1991;145:184-187.

4. Roberts TA, Ryan SA. Tattooing and high-risk behavior in adolescents. Pediatrics 2002;110:1058-1063.

5. Carroll ST, Riffenburgh RH, Roberts TA, Myhre EB. Tattoos and body piercings as indicators of adolescent risk-taking behaviors. Pediatrics 2002;109:1021-1027.

6. Bicca JF, Duquia RP, Breunig J de A, Souza PR, Almeida HL Jr. Tattoos on 18-year-old male adolescents-characteristics and associated factors. An Bras Dermatol 2013;88:925-928.
7. Koch JR, Roberts AE, Armstrong ML, Owen DC. Tattoos, gender, and well-being among American college students. Soc Sci J 2015;52:536-541.

8. D’Ambrosio A, Casillo N, Martini V. Piercings and tattoos: psychopathological aspects. Act Nerv Super Rediviva 2013;55:143-148.

9. Deschesnes M, Finès $P$, Demers $S$. Are tattooing and body piercing indicators of risk-taking behaviours among high school students? J Adolesc 2006;29:379-393.

10. Dukes RL. Deviant ink: a meta-analysis of tattoos and drug use in general populations. Deviant Behav 2016;37:665-678.

11. King KA, Vidourek RA. Getting inked: tattoo and risky behavioral involvement among university students. Soc Sci J 2013;50:540-546.

12. Koch JR, Roberts AE, Armstrong ML, Owen DC. Body art, deviance, and American college students. Soc Sci J 2010;47:151-161.

13. Koch JR, Roberts AE, Armstrong ML, Owen DC. College students, tattoos, and sexual activity. Psychol Rep 2005;97:887-890.

14. Ammerman BA, Jacobucci R, Kleiman EM, Uyeji LL, McCloskey MS. The relationship between nonsuicidal self-injury age of onset and severity of self-harm. Suicide Life Threat Behav 2017;48:31-37.

15. Dhossche D, Snell KS, Larder S. A case-control study of tattoos in young suicide victims as a possible marker of risk. J Affect Disord 2000;59: 165-168.

16. Aizenman M, Jensen MA. Speaking through the body: the incidence of self-injury, piercing, and tattooing among college students. J Coll Couns 2007;10:27-43.

17. Stirn A, Hinz A. Tattoos, body piercings, and self-injury: Is there a connection? Investigations on a core group of participants practicing body modification. Psychother Res 2008;18:326-333.

18. Stirn A, Hinz A, Brahler E. Prevalence of tattooing and body piercing in Germany and perception of health, mental disorders, and sensation seeking among tattooed and body- pierced individuals. J Psychosom Res 2006;60:531-534.

19. Dukes RL, Stein JA. Ink and Holes: correlates and predictive associations of body modification among adolescents. Youth Soc 2011;43: 1547-1569.

20. Silver E, VanEseltine M, Silver SJ. Tattoo acquisition: a prospective study of adolescents. Deviant Behav 2009;30:511-538.

21. Favazza AR, Rosenthal RJ. Varieties of pathological self-mutilation. Behav Neurol 1990;3:77-85.

22. Favazza AR, Rosenthal RJ. Diagnostic issues in self-mutilation. Psychiatr Serv 1993;44:134-140.

23. Diagnostic and Statistical Manual of Mental Disorders (DSM-5). 5th Ed. Arlington, TX; American Psychiatric Association; 2013.

24. Emiliano-Altamirano I, Albores-Gallo L. "Validación de una cédula diagnóstica de autolesiones en un hospital psiquiátrico infantil de la Ciudad de México". [Especialidad de Psiquiatría infantil y de la Adolescencia]. Ciudad de México: Universidad Nacional Autónoma de México; 2014.

25. Cossio T ML, Giesen FL, Araya G, Pérez-Cotapos S ML. Association between tattoos, piercings and risk behaviors in adolescents. Rev Médica Chile 2012;140:198-206.

26. Yen CF, Hsiao RC, Yen JY, Yeh YC, Wang PW, Lin HC, et al. Tattooing among high school students in southern Taiwan: the prevalence, correlates and associations with risk-taking behaviors and depression. Kaohsiung J Med Sci 2012;28:383-389.

27. Claes L, Vandereycken W, Vertommen H. Self-care versus self-harm: piercing, tattooing, and self-injuring in eating disorders. Eur Eat Disord Rev 2005;13:11-28.

28. Armstrong ML, Owen DC, Roberts AE, Koch JR. College students and tattoos: Influence of image, identity, family, and friends. J Psychosoc Nurs Ment Health Serv 2002;40:20-29.

29. Burger TD, Finkel D. Relationships between body modifications and very high-risk behavior in a college population. Coll Stud J 2002;36: 203-214.

30. Drews DR, Allison CK, Probst JR. Behavioral and self-concept differences in tattooed and nontattooed college students. Psychol Rep 2000; 
86:475-481.

31. Hill BM, Ogletree SM, McCrary KM. Body modifications in college students: Considering gender, self-esteem, body appreciation, and reasons for tattoos. Coll Stud J 2016;50:246-252.

32. Owen DC, Armstrong ML, Koch JR, Roberts AE. College students with body art. Well-being or risk behavior. J Psychosoc Nurs Ment Health Serv 2013;51:20-28.

33. Shaffer D, Jacobson C. Proposal to the DSM-V childhood disorder and mood disorder work groups to include non-suicidal self-injury (NSSI) as a DSM-V disorder. Am Psychiatr Assoc 2009;1-21.

34. Shaffer D, Colleen J. Proposal to the DSM-V Childhood Disorder and Mood Disorder Work Groups to Include Non-Suicidal Self-Injury (NSSI) as a DSM-V Disorder. Washington DC: American Psychiatric Association; 2010

35. Dulit RA, Fyer MR, Leon AC, Brodsky BS, Frances AJ. Clinical correlates of self-mutilation in borderline personality disorder. Am J Psychiatry 1994;151:1305-1311.

36. Matsumoto T, Yamaguchi A, Chiba Y, Asami T, Iseki E, Hirayasu Y. Patterns of self-cutting: a preliminary study on differences in clinical implications between wrist- and arm-cutting using a Japanese juvenile detention center sample. Psychiatry Clin Neurosci 2004;58:377-382.

37. Brunner R, Parzer P, Haffner J, Steen R, Roos J, Klett M, et al. Prevalence and psychological correlates of occasional and repetitive deliberate selfharm in adolescents. Arch Pediatr Adolesc Med 2007;161:641-649.

38. Muehlenkamp JJ, Brausch AM, Washburn JJ. How much is enough? Examining frequency criteria for NSSI disorder in adolescent inpatients. J Consult Clin Psychol 2017;85:611-619.

39. Selby EA, Kranzler A, Fehling KB, Panza E. Nonsuicidal self-injury disorder: the path to diagnostic validity and final obstacles. Clin Psychol Rev 2015;38:79-91.

40. Brausch AM, Muehlenkamp JJ, Washburn JJ. Nonsuicidal self-injury disorder: does Criterion B add diagnostic utility? Psychiatry Res 2016; 244:179-184.

41. Albores-Gallo L, Méndez-Santos JL, Xochitl-García Luna A, Delgadillo-Gonzalez Y, Chávez-Flores CI, Martínez OL. Nonsuicidal self-injury in a community sample of older children and adolescents of México City. Actas Esp Psiquiatr 2014;42:159-168.

42. Barrocas AL, Hankin BL, Young JF, Abela JRZ. Rates of nonsuicidal self-injury in youth: age, sex, and behavioral methods in a community sample. Pediatrics 2012;130:39-45.

43. Sornberger MJ, Heath NL, Toste JR, McLouth R. Nonsuicidal self-injury and gender: patterns of prevalence, methods, and locations among adolescents. Suicide Life Threat Behav 2012;42:266-278.

44. Castro Silva E, Benjet C, Juárez García F, Jurado Cárdenas S, Lucio Gómez-Maqueo ME, Valencia Cruz A, et al. Non-suicidal self-injuries in a sample of Mexican university students. Salud Ment 2017;40:191-200.

45. Iannaccone M, Cella S, Manzi SA, Visconti L, Manzi F, Cotrufo P. My body and me: self-injurious behaviors and body modifications in eating disorders-- preliminary results. Eat Disord 2013;21:130-139.

46. Victor SE, Muehlenkamp JJ, Hayes NA, Lengel GJ, Styer DM, Washburn JJ. Characterizing gender differences in nonsuicidal self-injury: evidence from a large clinical sample of adolescents and adults. Compr Psychiatry 2018;82:53-60.

47. Whitlock J, Eckenrode J, Silverman D. Self-injurious behaviors in a college population. Pediatrics 2006;117:1939-1948.

48. Whitlock J. Self-injurious behavior in adolescents. PLoS Med 2010;7: e1000240.

49. Csorba J, Dinya E, Plener P, Nagy E, Páli E. Clinical diagnoses, characteristics of risk behaviour, differences between suicidal and non-suicidal subgroups of Hungarian adolescent outpatients practising selfinjury. Eur Child Adolesc Psychiatry 2009;18:309-320.

50. Nixon MK, Cloutier PF, Aggarwal S. Affect regulation and addictive aspects of repetitive self-injury in hospitalized adolescents. J Am Acad Child Adolesc Psychiatry 2002;41:1333-1341.

51. Bunderla T, Gregorič H. Altered pain perception in self-injurious behavior and the association of psychological elements with pain perception measures: a systematic review. Psychiatr Danub 2015;27:346-354.

52. Benjet C, González-Herrera I, Castro-Silva E, Méndez E, Borges G, Casanova L, et al. Non-suicidal self-injury in Mexican young adults: Prevalence, associations with suicidal behavior and psychiatric disorders, and DSM-5 proposed diagnostic criteria. J Affect Disord 2017; 215:1-8.

53. Ekinci O, Topcuoglu V, Sabuncuoglu O, Berkem M, Akin E, Gumustas FO. The association of tattooing/body piercing and psychopathology in adolescents: a community based study from Istanbul. Community Ment Health J 2012;48:798-803.

54. Hicinbothem J, Gonsalves S, Lester D. Body modification and suicidal behavior. Death Stud 2006;30:351-363.

55. Brooks TL, Woods ER, Knight JR, Shrier LA. Body modification and substance use in adolescents: is there a link? J Adolesc Health 2003; 32:44-49.

56. Stephens MB. Behavioral risks associated with tattooing. Fam Med 2003;35:52-54.

57. Armstrong ML, Murphy KP. Tattooing: another adolescent risk behavior warranting health education. Appl Nurs Res 1997;10:181-189.

58. Groschwitz RC, Kaess M, Fischer G, Ameis N, Schulze UME, Brunner $\mathrm{R}$, et al. The association of non-suicidal self-injury and suicidal behavior according to DSM-5 in adolescent psychiatric inpatients. Psychiatry Res 2015;228:454-461. 